\title{
The effect of curing conditions on the strength development of cemented backfill samples
}

\author{
Brendan Dennis \\ Laboratory Supervisor, Outotec SEAP \\ Matthew Helinski \\ Process Technology Manager, Outotec SEAP
}

SUMMARY: Historically, strength development in underground backfill is estimated based on the results of historic unconfined compressive strength (UCS) testing. During both preliminary study phases and operational phases are batched to specific solids and binder contents and placed in curing chambers, with the intention that these chambers replicate the curing conditions experienced underground.

The rate of strength development in mining backfill can be greatly affected by variations in environmental factors including temperature \& humidity. Therefore accurate representation of in situ curing conditions for cemented specimens is crucial.

This paper investigates the effect that differing curing conditions can have on the strength development of cemented mine backfill specimens. This paper explores how variations expected to be encountered in typical fill masses impacts the resulting strengths and also investigates how aspects that may appear subtle can actually have a significant impact on the resulting measured strengths. Given the findings of this investigation a series of recommendations are provided for improving the way mine backfill curing chambers are managed.

Keywords: cemented backfill, curing conditions, temperature, quality control testing

\section{INTRODUCTION}

Historic evidence from temperature monitoring within fill masses during curing show a consistent trend of increasing temperatures during the initial stages of curing followed by a plateau in temperature, with most cases plateauing at temperatures well in excess of $35^{\circ} \mathrm{C}$. The increased temperature is expected to be a result of the exothermic cement reaction, while the sustained higher temperatures are expected to be due to the fills thermal mass. Examples of in situ temperature monitoring during filling, at various sites throughout the world are presented in Figure 1.

While it is widely recognised that curing temperature can significantly impact the strength of cementation materials, literature reviews show little record of controlled studies to quantify the impact of temperature on fill strengths in the context of how this may be relevant to onsite quality control testing.

This paper presents an investigation into the influence of curing temperature on the strength of different mine backfill types giving consideration to both; the magnitude of strength change that can occur as a result of temperature variations, and aspects that may appear subtle, but can actually have a significant impact on the quality control specimen curing temperatures, and therefore strengths measured in onsite quality control testing. The results from this testwork and analysis culminate in a series of recommendations for good practice quality control testing. 


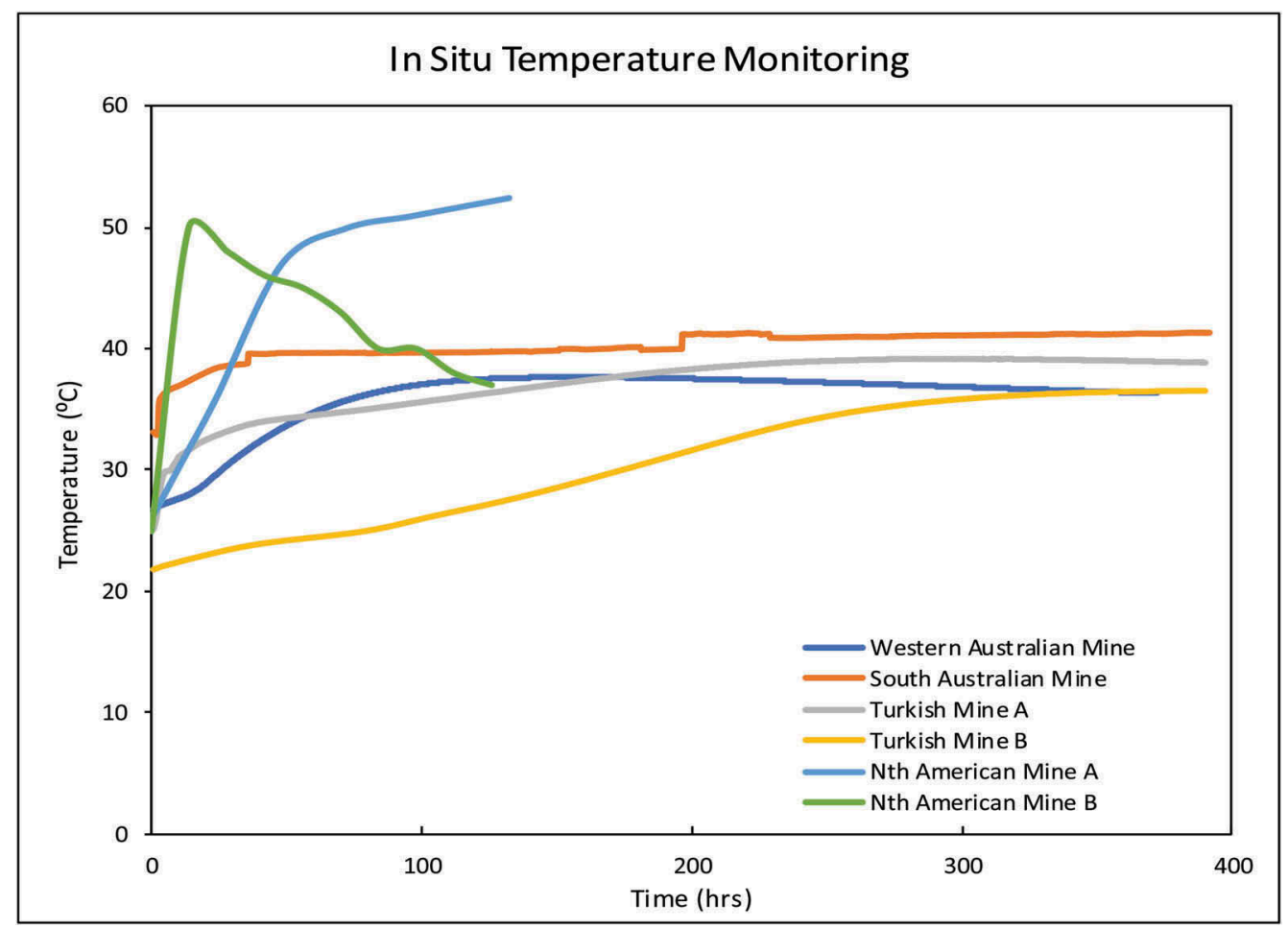

Figure 1. In situ fill mass temperature data from various underground mines.

\section{CURING TEMPERATURE SENSITIVITY}

To investigate this influence of curing temperature on fill strength, a series of cemented hydraulic fill mixes were batched with a range of different binder types and specimens for each mix. The samples were cured at temperatures of $23^{\circ} \mathrm{C}$ and $35^{\circ} \mathrm{C}$. The hydraulic fill adopted in this work was a copper tailings material that was predominantly Quartz and Chlorite minerals. All mixes were batched to $69 \%$ solids with $10 \%$ binder addition. Specimens batched for each mix were tested for unconfined compressive strength after hydration periods of 2, 7 and 28 days. The fill mix matrix is presented in Table 1.

The results from this testwork are presented in Figure 2, which shows the measured unconfined compressive strength (UCS) after 2,7 and 28 days hydration. Mixes cured at $35^{\circ} \mathrm{C}$ are presented as solids bars, while the equivalent mix cured at $23^{\circ} \mathrm{C}$ are presented as open bars.

Table 1. Experiment mix matrix.

\begin{tabular}{lllll}
\hline $\begin{array}{l}\text { Mix } \\
\text { No }\end{array}$ & Binder & $\begin{array}{l}\text { Binder portion } \\
(\%)\end{array}$ & $\begin{array}{l}\text { Curing Temp } \\
\left({ }^{\circ} \mathrm{C}\right)\end{array}$ & $\begin{array}{l}\text { Mix Solids Content } \\
(\%)\end{array}$ \\
\hline 1 & $\begin{array}{l}\text { General Purpose (GP) } \\
\text { Cement }\end{array}$ & 10 & 35 & 69 \\
& General Purpose (GP) & 10 & 23 & 69 \\
2 & Cement & 10 & 35 & 69 \\
3 & GP 75\%/Fly Ash 25\% & 10 & 23 & 69 \\
4 & GP 75\%/Fly Ash 25\% & 10 & 35 & 69 \\
5 & GP 65\%/Slag 35\% & 10 & 23 & 69 \\
6 & GP 65\%/Slag 35\% & & \\
\hline
\end{tabular}




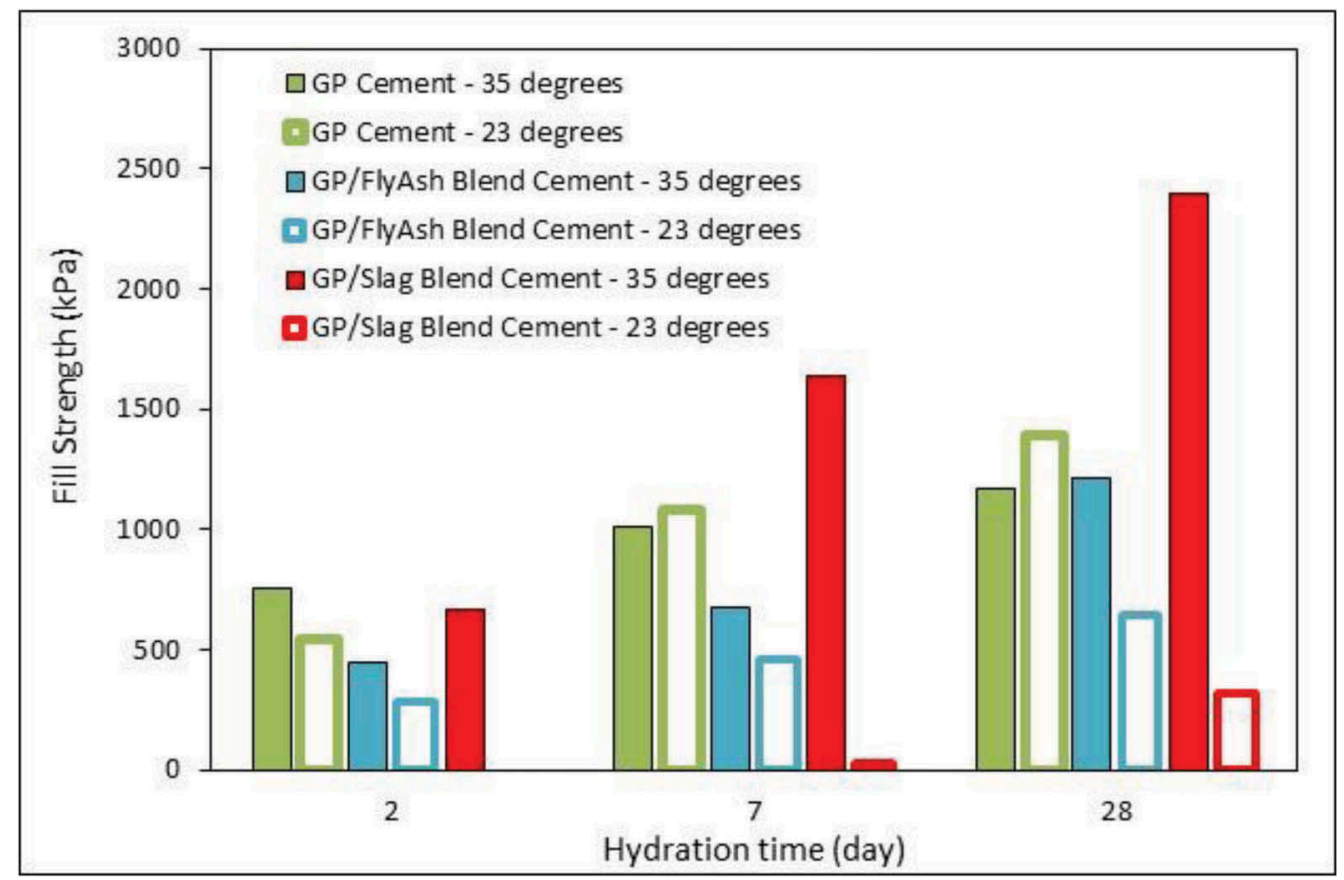

Figure 2. Influence of curing temperature on strengths for fill batched with different binders at different curing temperatures.

Figure 2 shows a direct correlation between curing temperature and strength, with all mixes showing higher strengths when cured at higher temperatures. However, what is most interesting about these figures is that, when cured at $23^{\circ} \mathrm{C}$ the GP/Slag blend binder shows little strength gain. However, when the same mix is cured at the higher temperature $\left(\right.$ of $\left.35^{\circ} \mathrm{C}\right)$ the resulting strengths are superior to all other mixes.

These results show that, compared with conventional concrete curing temperatures (of $23^{\circ} \mathrm{C}$ ), not only does curing cemented backfill specimens at temperatures more representative of in situ yield higher strengths, but the elevated temperature also shows different binder types to be more efficient.

To investigate the sensitivity of more subtle temperature changes in curing temperature, over the range of temperatures measured in situ, a second testwork campaign was initiated. This campaign considered an Australian paste fill mix with high silica content tailings and a binder blend type that consists of 30\% GP/70\% Ground Granulated Blast Furnace Slag (Slag). The mix was cast at $70 \%$ solids with $4 \%$ binder addition. Immediately after casting, specimens from this mix were placed into curing chambers that were set to different temperatures. One chamber (Chamber 1) was set to $35^{\circ} \mathrm{C}$, another (Chamber 2) set to $31^{\circ} \mathrm{C}$ and another (Chamber 3) set to a temperature of $43^{\circ} \mathrm{C}$. Specimens were cast in $50 \mathrm{~mm}$ diameter moulds and subject to UCS testing after 3, 7 and 28 days hydration.

The measured strengths, after 3,7 and 28 days hydration, are plotted against curing temperature in Figure 3.

Whilst it is widely acknowledged that curing temperature can influence the strength of cured paste backfill, Figure 3 shows that, across the range of temperatures measured within fill masses, the influence of temperature on strength can be significant (at 30-200\%). Given the variability of in situ temperatures presented in Figure 1 and the sensitivity of strength to temperature presented in Figure 3, a concerted effort should be dedicated to defining in situ curing temperatures for each individual site and ensuring that quality control specimens are cured under representative conditions. 


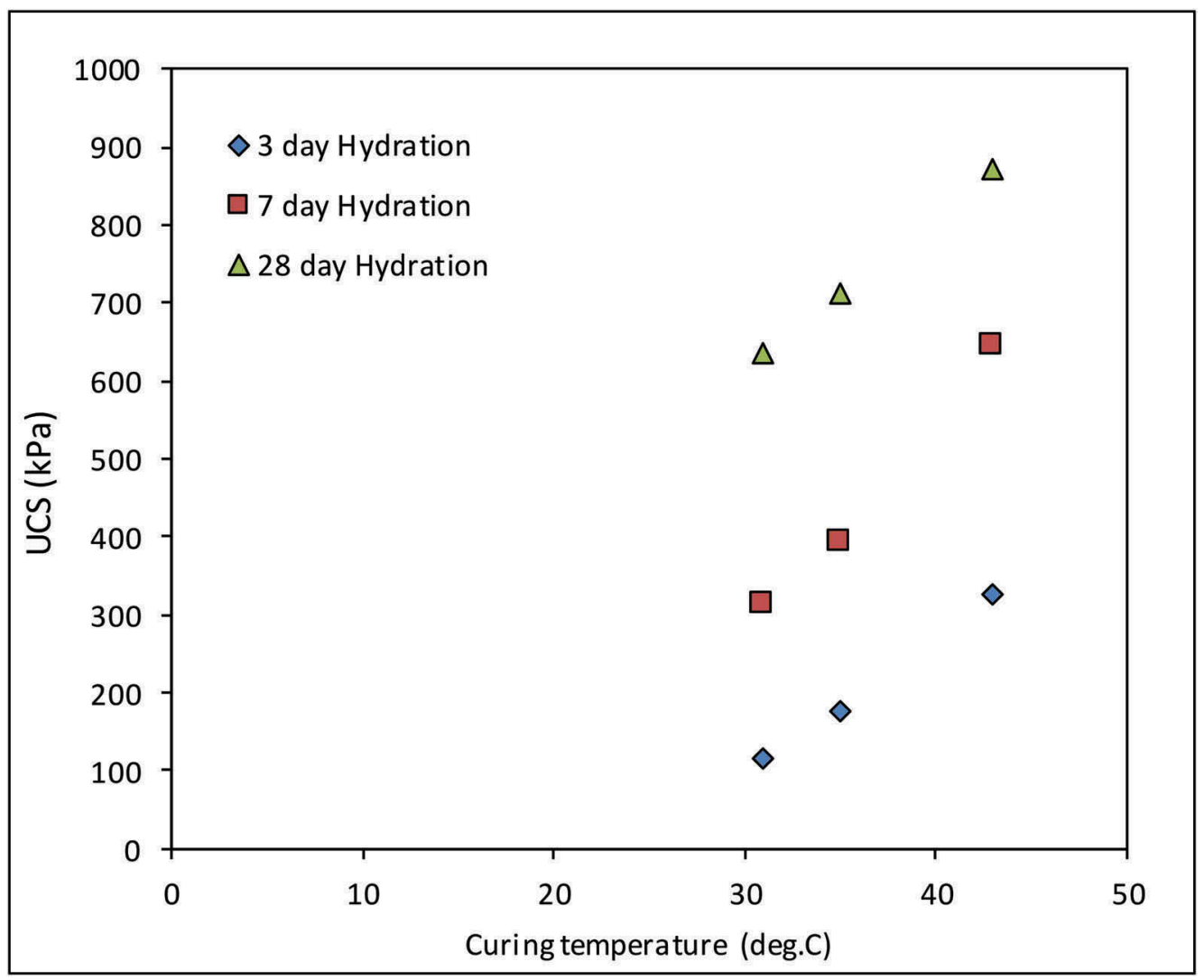

Figure 3. Influence of curing temperature on strengths of cemented paste fill samples.

\section{QUALITY CONTROL CURING METHODS}

Given the sensitivity of mine backfill strength to curing temperature, the authors set about to investigate how subtle aspects associated with onsite quality control curing methods may impact the measured strengths. A study was initiated to define the sensitivities around a typical curing chamber that may be used on site. The aim was to assess the influence of curing chamber size, and position within the curing chamber, on the curing conditions and resulting strength.

For this study, two curing chambers were utilised. Chamber \#1 is a $1200 \times 900 \times 600 \mathrm{~mm}$ unit with one element and one thermostat. Chamber \#3 is a larger $1600 \times 1200 \times 800 \mathrm{~mm}$ unit with three elements and one thermostat. Chambers are manufactured from $4 \mathrm{~mm}$ aluminium sheeting, but other models may be manufactured from stainless steel of similar thickness. Each curing chamber was set with the thermostat and heat coil submerged in $100 \mathrm{~mm}$ of water at the base of the chamber. Above the water line a horizontal mesh layer is inserted, and specimens are placed on this mesh. To meet capacity requirements specimens can be stacked in these chambers so some specimens may be cured up to $250 \mathrm{~mm}$ above the water line. This arrangement is typical of curing chambers adopted for onsite quality control testing in Australia. A photograph inside a curing chamber is presented in Figure 4.

For the first mix comparison, a total of 6 locations were selected within these chambers. These include L1, L2 and L4 in the larger Chamber \#3 and L6, L7 and L8 in the smaller Chamber \#1. L1, L6 and L7 were located on the chamber floor (immediately above the waterline), whilst L2, L4 and L8 were raised to a height of $250 \mathrm{~mm}$ above the waterline. 


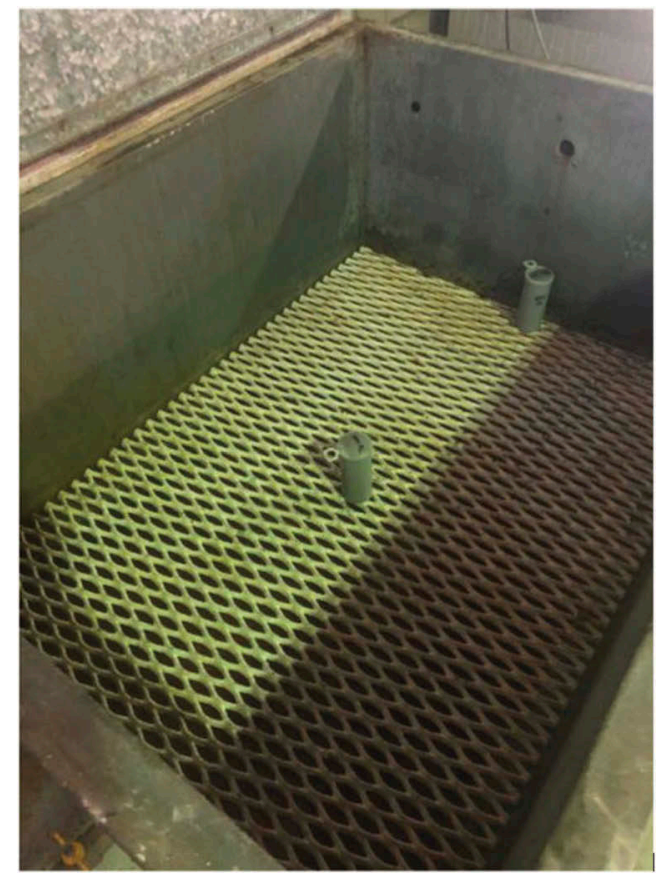

Figure 4. Photograph of curing chamber used in experiments.

Images showing the location of these specimens on a plan view of the chambers is presented in Figure 5.

Paste for all specimens was batched in a single mix, which contained $4 \%$ binder batched to $70 \%$ solids. Samples were tested in duplicate for each location and hydration period. Samples were cast in $50 \mathrm{~mm}$ diameter moulds, and samples from each location were tested for UCS after 4, 7 and 28 days hydration. Specimens were also cast for long-term testing (at 240 days hydration), however these were yet to be tested at the time of compiling this document.

The measured strength is plotted against hydration time in Figure 6. Figure 6a presents the measured strength for specimens cured in the larger chamber (Chamber \#3), while specimens cured in the smaller chamber (Chamber \#1) are presented in Figure 6b. The results presented in Figures $6 \mathrm{a}$ and $\mathrm{b}$ are the average of the duplicate samples in each location, and it should be noted that the standard deviation of the duplicate samples was less than $10 \%$ for all cases.

The results presented in Figures 6a and b show that, for the same mix, in what may have been be considered identical curing environments, the measured 28 -day strength varied by over $30 \%$,

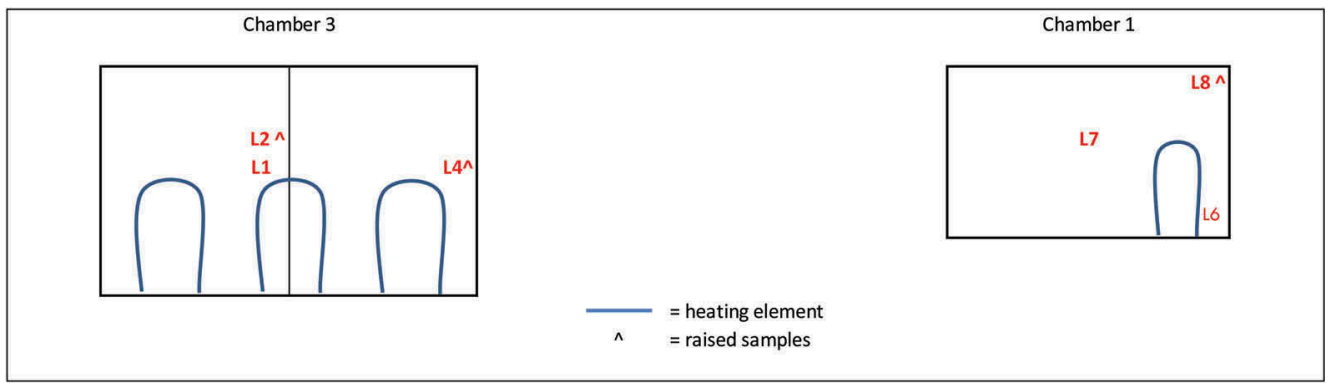

Figure 5. Position of heating elements and specimen location within chambers. 
across a given chamber and up to $60 \%$ across both chambers. Analysis of the test specimens showed that, across all specimens, dry densities were within $0.01 \mathrm{t} / \mathrm{m}^{3}$, while saturation levels were all between 98 and $100 \%$, which suggests mix variability was not contributing to the strength discrepancy.

To investigate the source of this strength discrepancy environmental testing was undertaken at a range of different locations throughout each of the curing chambers. All probes showed consistently high relative humidity (in excess of $98 \%$ ), but a notable variation in curing temperatures. The measured curing temperatures in Chamber \#3 and \#1 are plotted against time in Figure $7 \mathrm{a}$ and $\mathrm{b}$, respectively. It should be noted that the zig-zag temperature profile is a result of the heating element engaging to raise the temperature.

Figure 7 shows a temperature variation or upto $14 \%$ across a given curing chamber and when comparing Figures $7 \mathrm{a}$ and $\mathrm{b}$, this shows that even though both chambers had the same setpoint, temperatures varied by $16 \%$ between chambers.

To assess the correlation between curing temperature and strength, the 7 and 28 day strengths are plotted against measured curing temperature in Figure 8. Superimposed over Figure 8 is the strength verses curing temperature relationships previously presented in Figure 3.

Figure 8 shows a consistent trend of increasing fill strength with curing temperature, which is similar to trends presented in Figure 3. Given this consistent trend and other similar fundamental specimen properties (e.g. dry density and moisture contents) it is expected that the

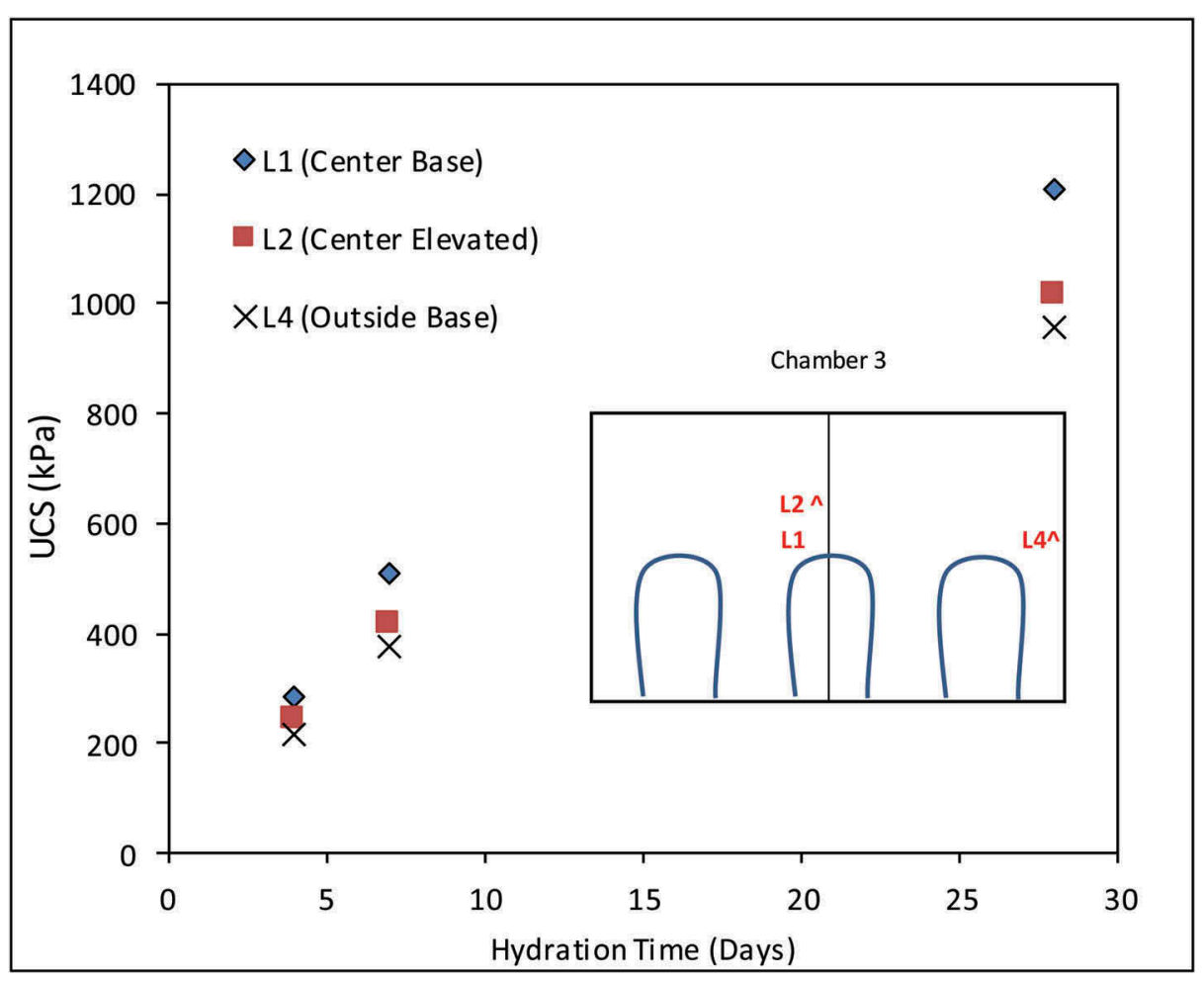

(a) 


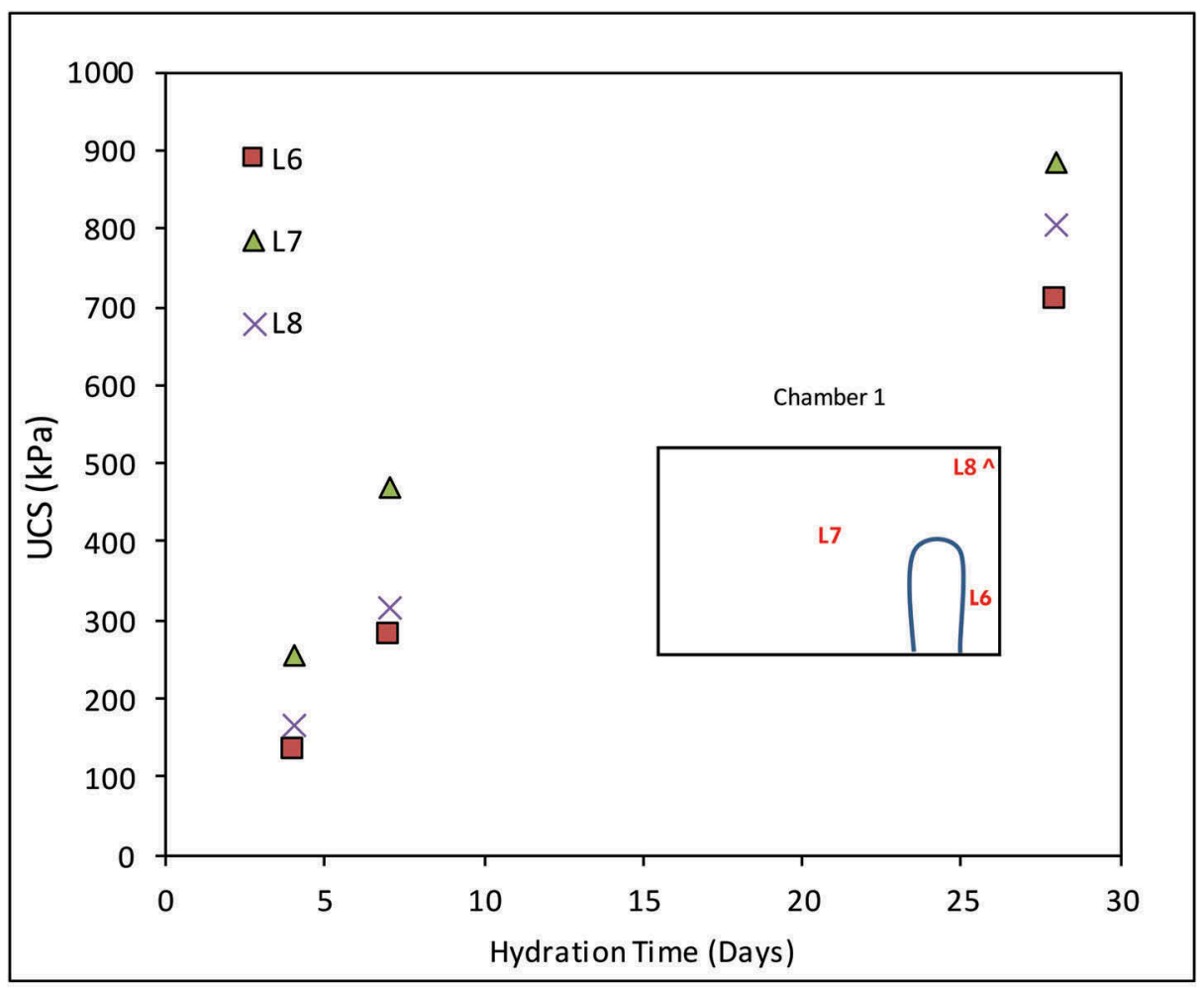

(b)

Figure 6. Strength against hydration time for specimens cured in different locations of a (a) large and (b) small curing chambers.

observed variability in strength is attributable to the variation in curing temperature across the chamber/s.

Given that many Australian mines are located in arid environments where ambient temperatures can vary by over $20^{\circ} \mathrm{C}$ between day and night, and by over $40^{\circ} \mathrm{C}$ over the year, and that site curing chambers are not necessarily located in temperature controlled facilities, variation in curing temperatures both across the chamber and due to ambient temperature variations could be having a significant impact on measured quality control strengths.

\section{CURING CONDITION MANAGEMENT}

Given the sensitivity of strength to curing temperature and the observed variation in temperature across conventional site based curing chambers, insulating wrapping was applied to a typical chamber in an effort to minimise heat exchange. Insulation adopted was an Air-Cell shield consisting of foam cell core and reflective wrapping. Chamber 1 was fully insulated whilst an identical chamber (Chamber 2) was not. A photograph showing the fully insulated chamber is presented in Figure 9. This figure also shows the environmental condition monitoring probes at the centre and edge of the chamber. 


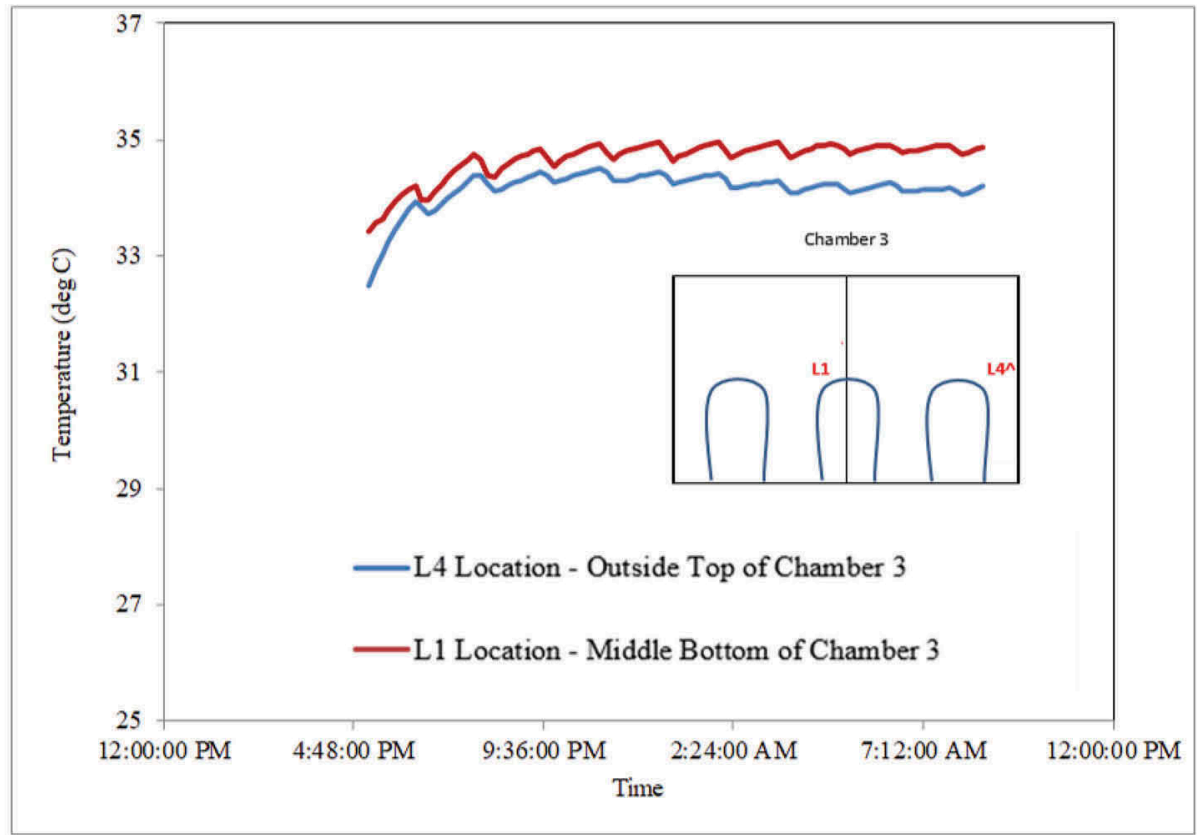

(a)

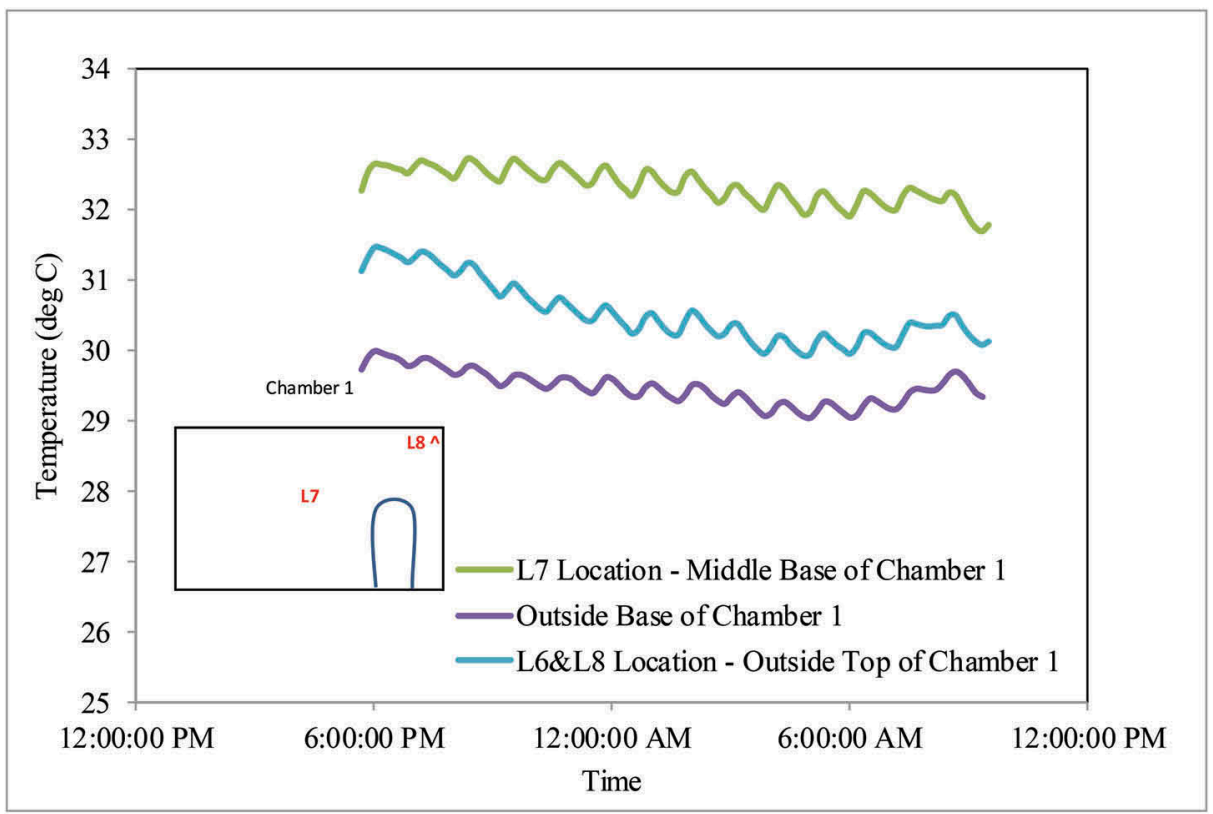

(b)

Figure 7. Hydration temperature against time for specimens cured in different locations of a (a) large and (b) small curing chambers. 


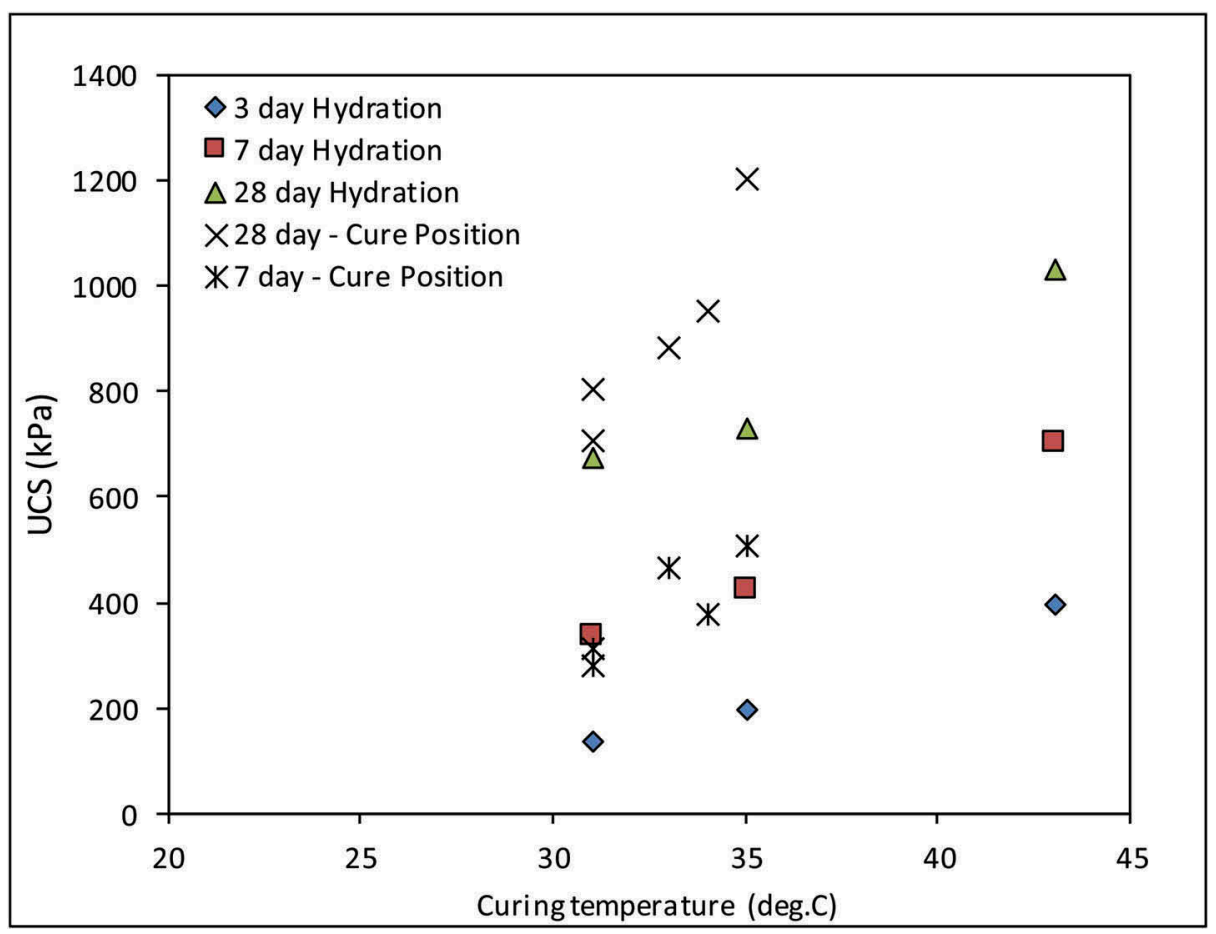

Figure 8. Strength against curing temperature for samples within the same curing chamber superimposed over the results from Figure 3.

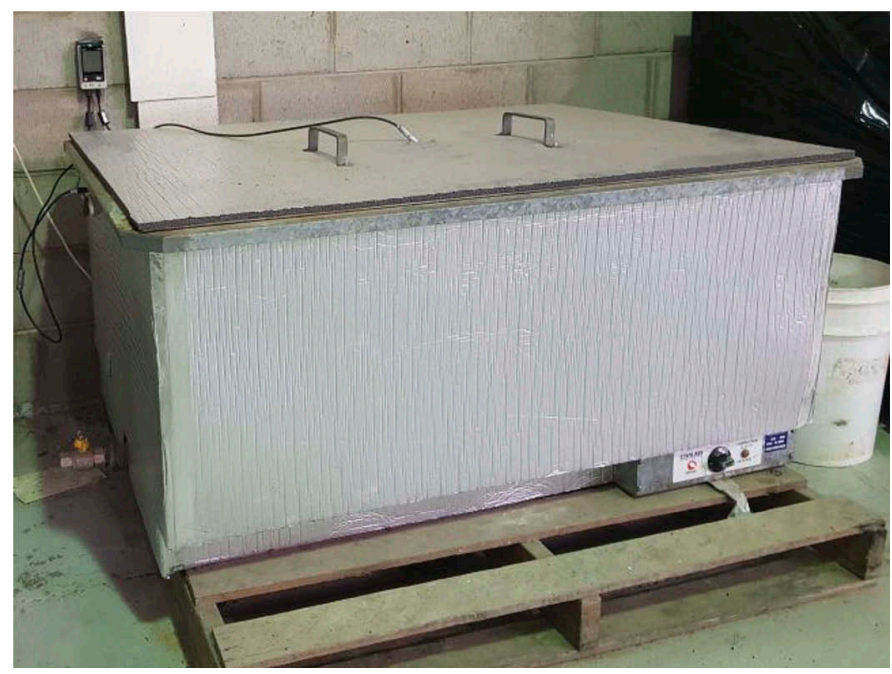

Figure 9. Photograph of insulated curing chamber. 


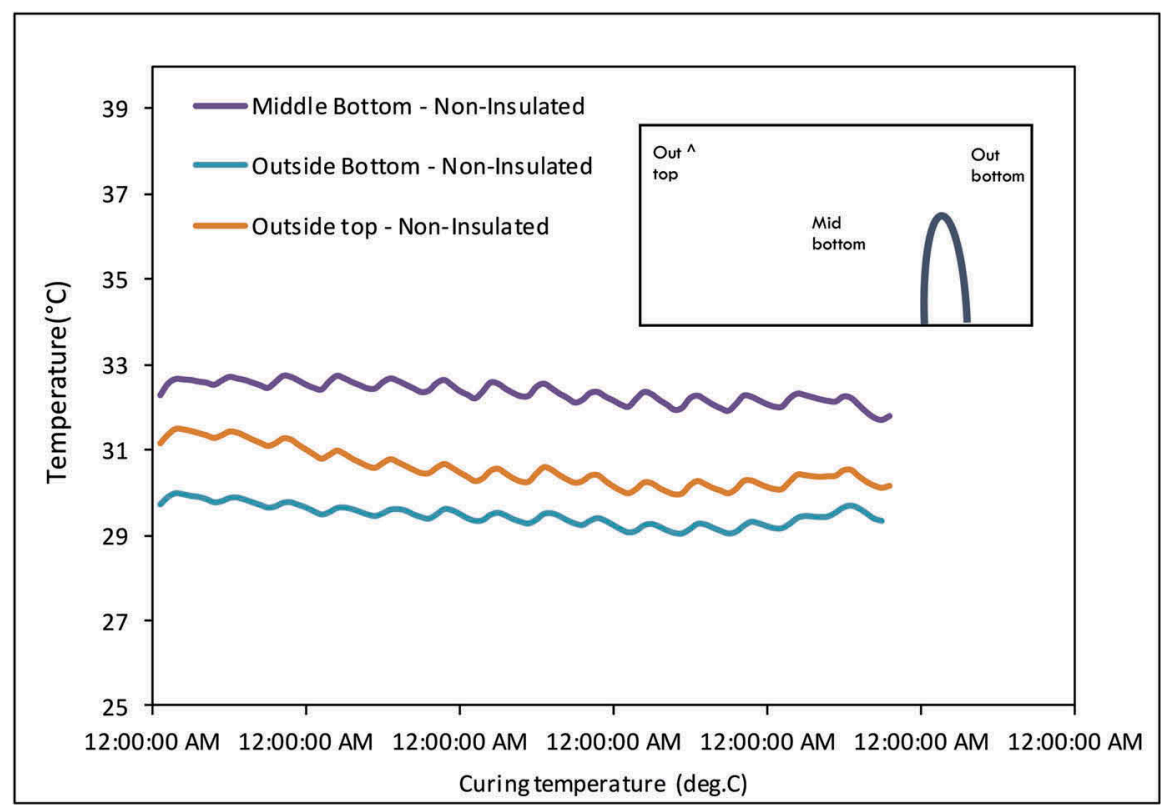

(a)

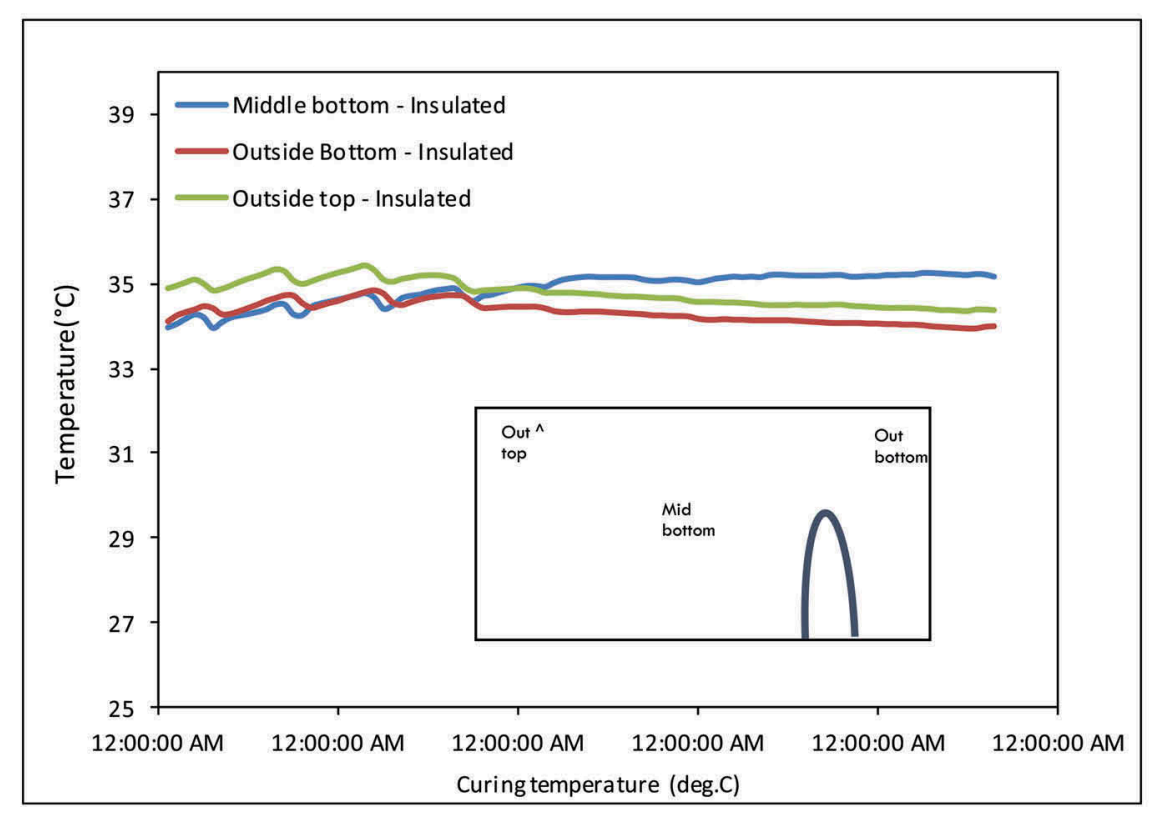

(b)

Figure 10. 3-location monitoring of chamber 1 (a) before and (b) after insulation. 
Both curing chambers were set at the same thermostat set-point (of $35^{\circ} \mathrm{C}$ ). Figure $10 \mathrm{a}$ and $\mathrm{b}$ present the temperature measurements at different locations within the uninsulated and insulated curing chambers, respectively.

Comparison between the temperature measurements in the insulated and non-insulated curing chambers show that, for the same thermostat setting, the insulated curing chamber provides a higher and more consistent temperature environment across the chamber.

To confirm the performance of specimens cured across the more consistent curing conditions a paste mix was cast and cured at locations L9-12 across the insulated curing chamber. The curing locations and measured strength (against hydration time) are presented in Figure 11.

The results presented in Figure 11 illustrate that the improved consistency of curing conditions across the chamber resulted in a significant improvement in the consistency of strength measured for specimens cured in different locations across the chamber.

The other notable feature about the increase in consistency of the curing conditions (from insulation) is the increase in temperature stability over time. Figure 12 presents a plot showing the variation in curing chamber temperature against time, for the insulated and uninsulated chambers. This figure shows the uninsulated chamber cycling in temperature in accordance with the ambient temperature during dan and night cycles. The insulated chamber shows a steady temperature regardless of the surrounding ambient temperature.

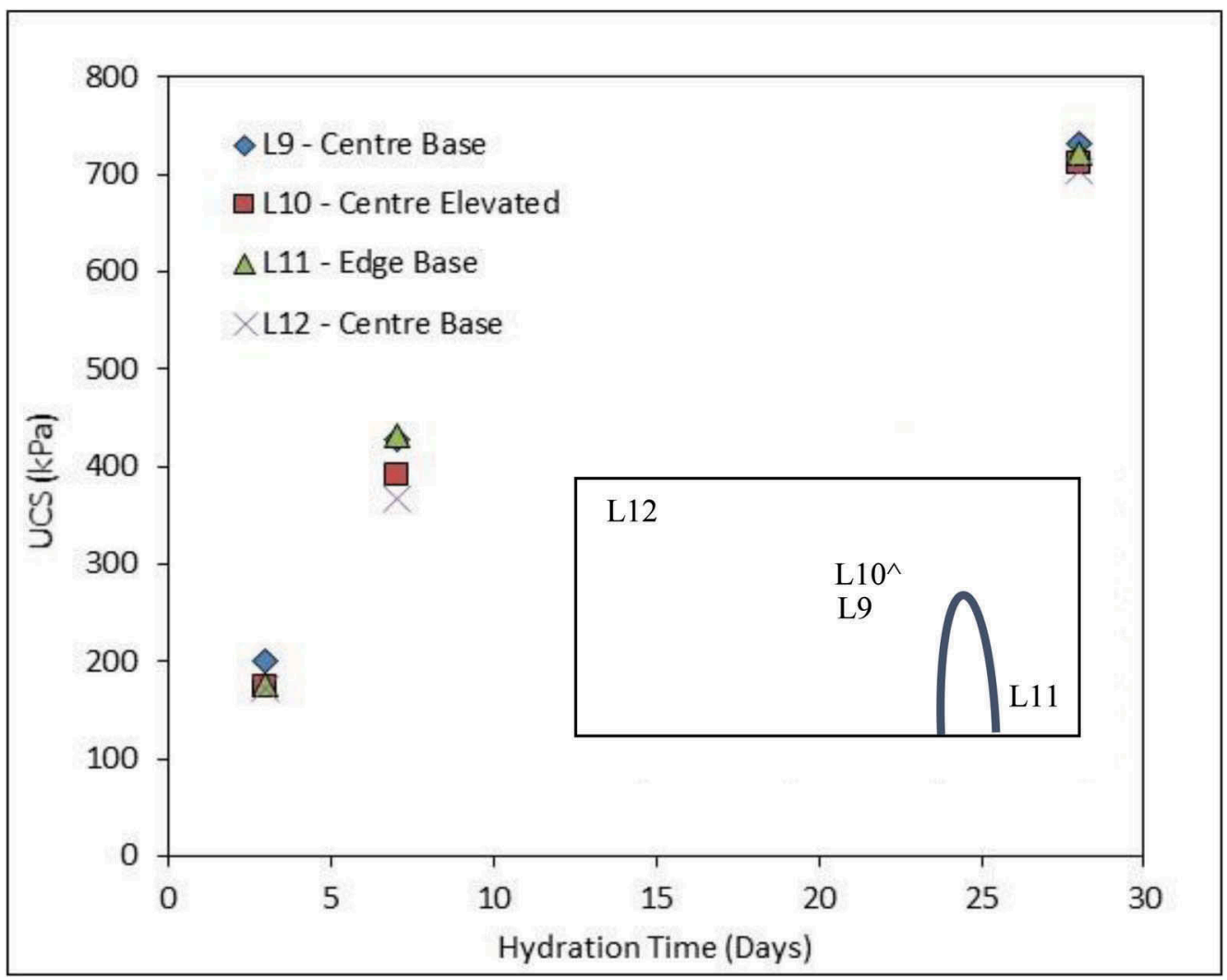

Figure 11. Strength against hydration time for specimens cured in insulated curing chamber. 


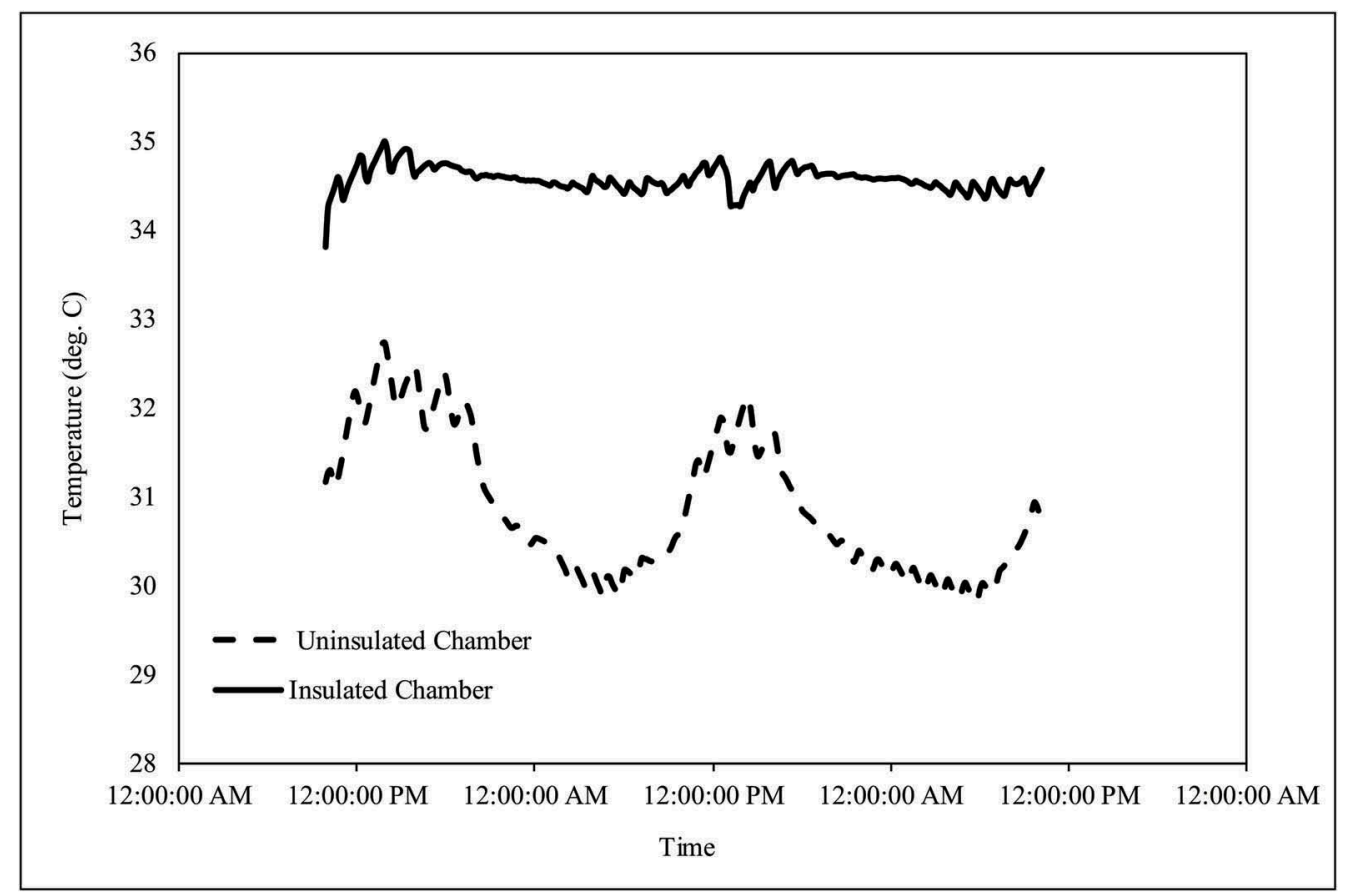

Figure 12. Curing chamber temperature cycles in insulated and uninsulated curing chambers.

\section{CONCLUSION}

This paper presents a study to investigate the influence of curing temperature on the strength of cemented paste backfill. While it is widely recognised that curing temperature has an influence on cemented backfill strengths and that insulation reduces heat transfer the interesting findings from this investigation showed that:

- Based on in situ data gathered from within cemented mine backfill masses, at various sites throughout the world, it can be seen that in situ curing temperatures are significantly higher (at $30-50^{\circ} \mathrm{C}$ ) than recommended concrete industry quality control curing temperatures $\left(23^{\circ} \mathrm{C}\right)$.

- Testing showed that, relative to specimens cured at recognised concrete industry curing temperatures, specimens cured at higher temperatures not only showed higher rates of strength gain, but also show different binder types (in this case GP/Slag blends) to be more efficient.

- Testing across the range of temperatures expected to be encountered in typical minefill masses (at $30-45^{\circ} \mathrm{C}$ ) show that, across this range, the strength of cemented paste backfill can vary by $30-200 \%$, with the most significant influence being at early hydration periods. On this basis it is considered critical that sites identify in situ curing conditions (temperature) and ensure that quality control specimens are cured at similar temperatures.

- Measurement of temperature variations across an uninsulated curing chamber showed that a thermostat feedback loop is insufficient for achieving steady curing conditions across the chamber. The magnitude of the temperature variation was shown to create a $30-60 \%$ difference in measured fill strengths depending on chamber size and specimen position. Given the observed variability, it is recommended that all laboratory and field based curing chambers are:

$\circ$ fitted with thermostats and properly sized heating coils. 
- properly insulated to eliminate a variation in temperature both across the curing chamber and due to variations of external ambient temperatures.

- fitted with multiple environmental sensors to confirm that the desired temperature and humidity are achieved throughout the chamber.

- In situ temperature measurements indicate a considerable change in fill curing temperatures over time. This aspect was not pursued as part of this investigation. However, given the sensitivity strength to curing temperature, it is recommended that future work be dedicated to developing rational strategies for curing quality control specimens under conditions that more accurately represent the evolution of curing temperature with hydration time. 